\title{
CHARACTERIZATION OF MICROGRAVITY ENVIRONMENT ON MIR
}

\author{
Hyoung M. Kim and Mohamed Kaouk \\ The Boeing Company, Houston, Texas
}

\begin{abstract}
SUMMARY
This paper presents the microgravity analysis results using dynamic response data collected during the first phase of the Mir Structural Dynamics Experiment (MiSDE). Although MiSDE was designed and performed to verify structural dynamic models, it also provided information for determining microgravity characteristics of the structure. This study analyzed ambient responses acquired during orbital day-to-night and night-today transitions, crew treadmill and ergometer exercises, and intentional crew activities. Acceleration levels for one-third octave bands were calculated to characterize the microgravity environment of the station. Spectrograms were also used to analyze the time transient nature of the responses. Detailed theoretical background and analysis results will also be included in the final draft.
\end{abstract}

\section{INTRODUCTION}

Assembly of the International Space Station (ISS) began in 1998 to provide the orbiting laboratory for conducting scientific research. These research activities require an extremely quiescent environment, called a microgravity mode, whose acceleration level is in the order of 1 micro-gravity. This is achieved through careful design of the station and its operation and, if necessary, through active isolation of individual experiments.

The Russian Mir (translated as "peace") Space Station is a permanently manned spacecraft which evolved from the previous Salyut Program. It consists of several modules, the first of which was launched in 1986. The U.S. has conducted various research on the Mir since 1992 to gain scientific knowledge and to mitigate risk associated with the ISS. One of them was the Mir Structural Dynamics Experiment (MiSDE), whose main objective was to determine the feasibility of correlating and refining math models of large space structures by on-orbit modal testing [1 4]. One of the MiSDE secondary objective was to provide information for determining microgravity characteristics.

The ISS system specification requires to provide a prescribed acceleration environment at a minimum of $50 \%$ of the internal user payload locations for 180 days per year in continuous time intervals of at least 30 days [5]. The disturbance allowable is specified for quasi-steady and vibratory accelerations. The frequency content of quasisteady accelerations is less than $0.01 \mathrm{~Hz}$ and vibratory acceleration frequencies range from $0.01 \mathrm{~Hz}$ to $300 \mathrm{~Hz}$. 
There are two distinct vibratory acceleration specifications. The first applies to the total combined acceleration level which is produced by all disturbance sources which occur simultaneously within any 100 second time window. The second applies to the acceleration level which is produced by a single transient source. The former was examined using the acceleration data obtained from the MiSDE. Since there are similarities between ISS and Mir components, especially at earlier ISS assembly stages, this study provided valuable information in predicting the microgravity environment on the ISS.

\section{INSTRUMENTATION AND TESTING}

\section{Instrumentation}

The Mir Auxiliary Sensor Unit (MASU) can measure acceleration with wide dynamic and frequency ranges of 3.6 micro-g to 120 milli-g and $0 \mathrm{~Hz}$ to $250 \mathrm{~Hz}$, respectively [1]. This system provides four levels of gain selection and 16-bit simultaneous sampling. The MASU consists primarily of an Experiment Support Module (ESM), a Distribution Box (DB), Accelerometer Heads (AHs), and associated cables. Data is stored on removable 260 MB Personal Computer Memory Card International Association (PCMCIA) hard disks.

MASU has five triaxial (three accelerometers aligned in orthogonal directions) and four uniaxial portable sensor units which were installed throughout Mir on the primary structure. Figure 1 shows the Shuttle-Mir mated configuration. A triaxial sensor is located in Core, Kvant-1, Priroda, Krystall, and Kvant-2. A uniaxial sensor is located in Core, Kvant-1, Krystall, and Spektr. These sensors are high fidelity, electro-mechanical servo accelerometers that also provide temperature output.

MASU was originally designed to obtain acceleration data for structural dynamic model verification. However, MASU can also provide information for determining microgravity characteristics of the structure. Some of the MiSDE sessions were also recorded by other Mir instrumentation systems $[6,7]$.

\section{Flight Testing}

The MiSDE on-orbit tests were performed from November 1996 to December 1997 and were categorized into two phases [2]. The first phase (primary) MiSDE tests were performed during the NASA-3 Long Duration Mission (LDM) which started after STS79 (Space Transportation System-Mission 79) and included STS-81. The second phase (follow-up) tests were performed during NASA-4 (including STS-84), NASA-5 (including STS-86), and NASA-6 (which ended prior to STS-89). In the second phase, data was obtained for new test sessions as well as those similar to the first phase test sessions, with modifications based on the first phase results.

After completing the installation of the MASU sensors and routing of their cables, the first phase MiSDE tests began in November 1996. These tests included nine sessions in the Mir alone configuration and seven sessions in the Shuttle-Mir mated configuration. 
Test sessions included: Shuttle and Mir thruster firings, Shuttle-Mir docking, crew exercise and pushoffs, and ambient noise during night-to-day and day-to-night orbital transitions. The test sessions were designed to provide a wide range of load paths, input force levels, and frequency contents. Some of the MiSDE sessions were also recorded by other Mir instrumentation systems.

Most of the MiSDE test sessions, such as Mir or Shuttle thruster firing sessions, were designed to produce large responses and to excite specific structural modes. However, MiSDE also recorded ambient responses that can be used for microgravity analysis. They included the data acquisition during orbital day-to-night and night-to-day transitions, crew treadmill and ergometer exercises, and intentional crew activities.

\section{DATA PROCESSING AND ANALYSIS}

\section{Data Processing Procedure}

The ISS requires that the combined acceleration environment $(a)$ for a given frequency range $(f)$ should be limited to the following levels [5]:

For $0.01 \mathrm{~Hz}<f<0.1 \mathrm{~Hz}: a<1.6$ micro-g

For $0.1 \mathrm{~Hz}<f<100 \mathrm{~Hz}: a<$ f $\times 16$ micro-g

For $100 \mathrm{~Hz}<f<300 \mathrm{~Hz}: a<1600$ micro-g

These levels, illustrated in Figure 2, correspond to a 100 second averaged, root-meansquare, magnitude limit which is defined at the center frequency of each of the one-third octave bands spanning the $0.01 \mathrm{~Hz}$ to $300 \mathrm{~Hz}$ frequency range. This magnitude limit is the root-sum-square of the acceleration responses from all three orthogonal axes. Table 1 identifies the one-third octave bands over a typical decade in the range which is used in the analysis.

The computational tool for the one-third octave band was developed on the MATLAB ${ }^{\mathrm{TM}}$ platform. The following describe the computational steps employed in the analysis:

1) Calculate the power spectral density (PSD) which is equivalent to the meansquare of the data in the time domain (Parseval's theorem). Average the PSD (or mean-square) over the pre-defined time window. Defer taking square-root (to make root-mean-square). 1 dos this meon

2) Calculate the sum-square of the value above (which is already squared) from all do not colculate three axes. Defer taking square-root (to make root-sum-square).

3) Integrate the value above over the pre-defined frequency bands.

4) Iterate Steps 1) to 3) over the entire data length.

5) Scale the value above to derive proper physical values.

6) Take square-root of the value above.

7) Find the maximum for each frequency band from the values above. 
Several computational steps were interchanged to minimize computation, but the final results were identical. The literal computational flow is as follows: averaged root-meansquare (PSD, average, scale, \& square-root), integration, root-sum-square (square, sum, \& square-root), iteration, and finding maximum.

In calculating the PSD over the pre-define time window (a 100 second in this case), PSDs for smaller sliding time windows were calculated and then averaged. Computation was reduced by selecting the number of data samples to be a power of 2 as well as by selecting a smaller time window. About half the data samples were overlapped between each PSDs to provide sufficient number of averages. The process adjusts the number of overlapped data samples by selecting the overlap closest to the initial user input, which produces a total number of data samples close to, but not to exceed, a 100 second time window. The hanning window was also used to reduce the leakage problem.

To satisfy the requirement, Step 4) should be applied to every 100 second period by sliding the time window by one data sample at a time. To reduce computation, the data was examined about every 50 seconds, one half of the 100 second window. This overlap of analysis window was also adjusted to cover the entire data set in a similar fashion to the PSD overlap previously described. Table 2 shows the typical analysis parameters selected and/or adjusted in the study.

\section{$\underline{\text { Data Analysis }}$}

Acceleration response data, collected during the first phase of the Mir Structural Dynamics Experiment (MiSDE) which began in November 1996, was used for microgravity analysis. These tests, described in Table 3, included nine sessions in the Mir alone configuration and seven sessions in the Shuttle-Mir mated configuration. Table 4 summarizes the maximum time-domain response levels measured by MASU. The responses used for Table 4 were filtered at $20 \mathrm{~Hz}$ with a lowpass filter to compare the response levels among different sessions with different sampling rates.

Table 5 summarizes the maximum response levels for each one-third octave band for Teble 5 , I sce whet selected test sessions. In general, for similar sessions, response levels for the Mir alone configuration are higher than those for the Shuttle-Mir mated configuration. Response levels for the thruster firing or Shuttle-Mir docking sessions are higher in the lower frequency bands. Figures 3 (a) and (b) show the maximum one-third octave band plot for the day-to-night orbital transition and Shuttle-Mir docking sessions, respectively.

Spectrogram plots enable to characterize frequency content variations of a response over time. Figures 4 (a) and (b) show the spectrogram plots for the crew treadmill exercise and Shuttle thruster firing sessions, respectively. Figure 4 (a) illustrates the frequency contents of the crew and treadmill interaction which can be used to deduce the crew member running speed. Figure 4 (b) shows the thruster firings and also resulting is sishificat, the response get lose abuc $20 \mathrm{~Hz}$. This misht need to be adtiessed in the selection of the $20 \mathrm{~Hz}$ low poss tilter structural responses. 


\section{REFERENCES}

[1] Kim, H.M. and Bokhour, E.B., "Mir Structural Dynamics Experiment: A Flight Experiment Development," Proc. 38th AIAA SDM Conference, Kissimmee, FL, Paper No. AIAA-97-1169, pp. 577-585, April 1997.

[2] Kim, H.M. and Kaouk, M., "Mir Structural Dynamics Experiment: First Phase Test and Data Analysis," Proc. 39th AIAA SDM Conference, Long Beach, CA, Paper No. AIAA-98-1721, pp. 204-212, April 1998.

[3] Kim, H.M. and Kaouk, M., "Mir Structural Dynamics Experiment: First Phase Test and Model Refinement," Proc. 40th AIAA SDM Conference, St. Louis, MO, Paper No. AIAA-99-1453, April 1999.

[4] Kim, H.M. and Kaouk, M., Final Report: Mir Structural Dynamics Experiment, The Boeing Company, 332 p., Dec. 1998.

[5] Microgravity Control Plan, NASA, International Space Station Program, SSP 50036, Rev. B (Draft), Par. 4.0, Feb. 1997.

[6] SAMS Acceleration Measurements on Mir From September 1996 to January 1997, NASA-LeRC, Document No. NASA/TM-97-206320, December 1997.

[7] Amir, A.R., Design and Development of Advanced Load Sensors for the International Space Station, MIT, Engineer Degree Thesis, 220 p., Sept. 1998. 


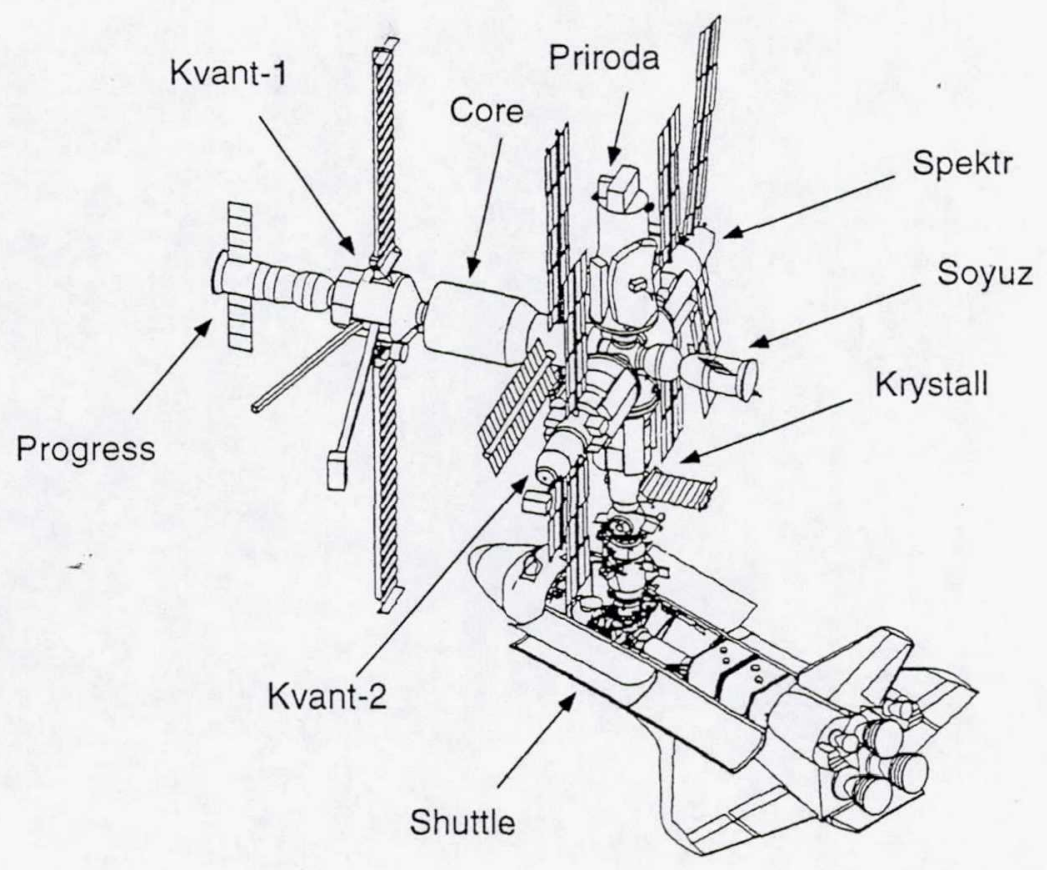

Figure 1. Shuttle-Mir Mated Configuration.

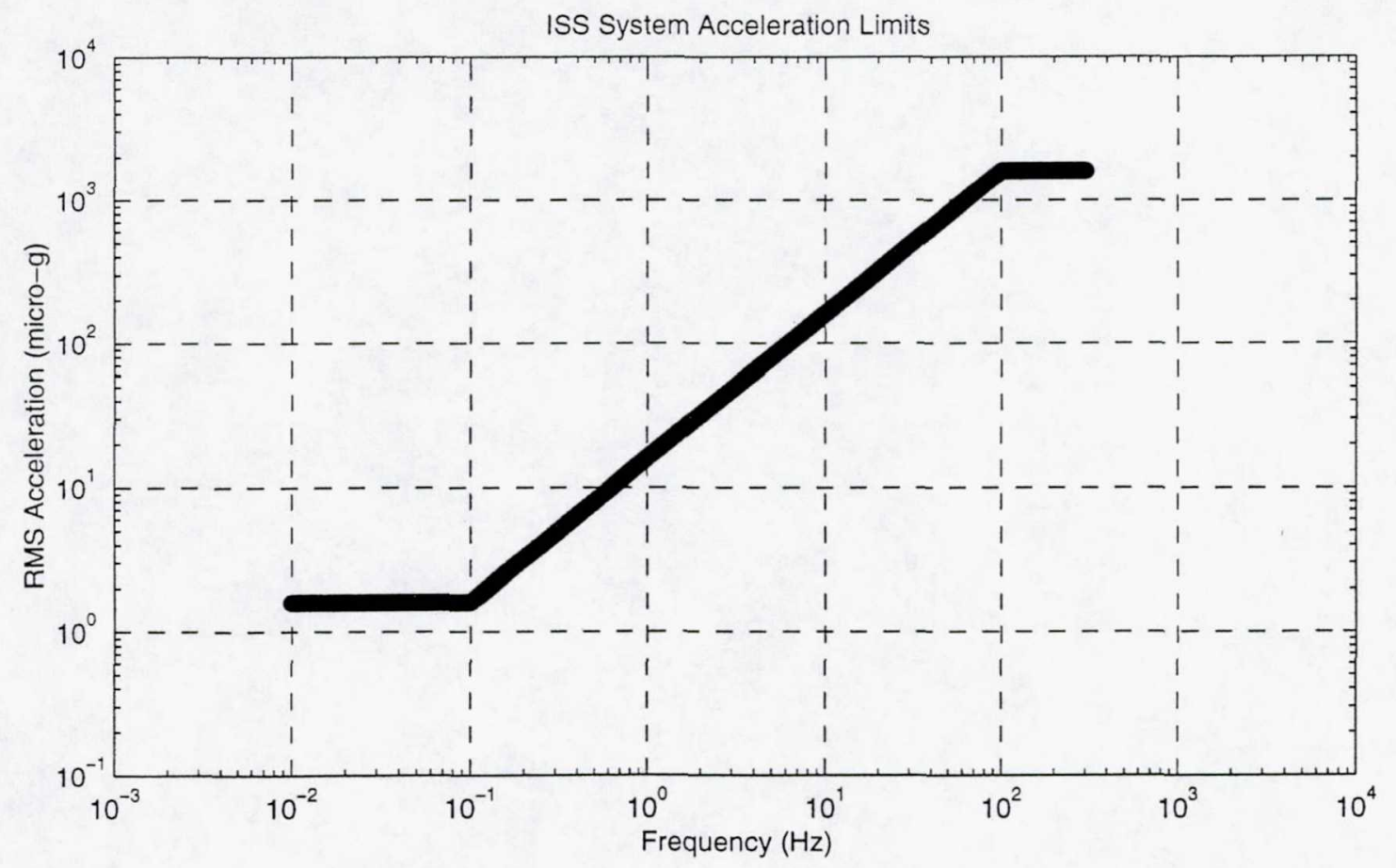

Figure 2. ISS System Combined Vibratory Acceleration Limits. 


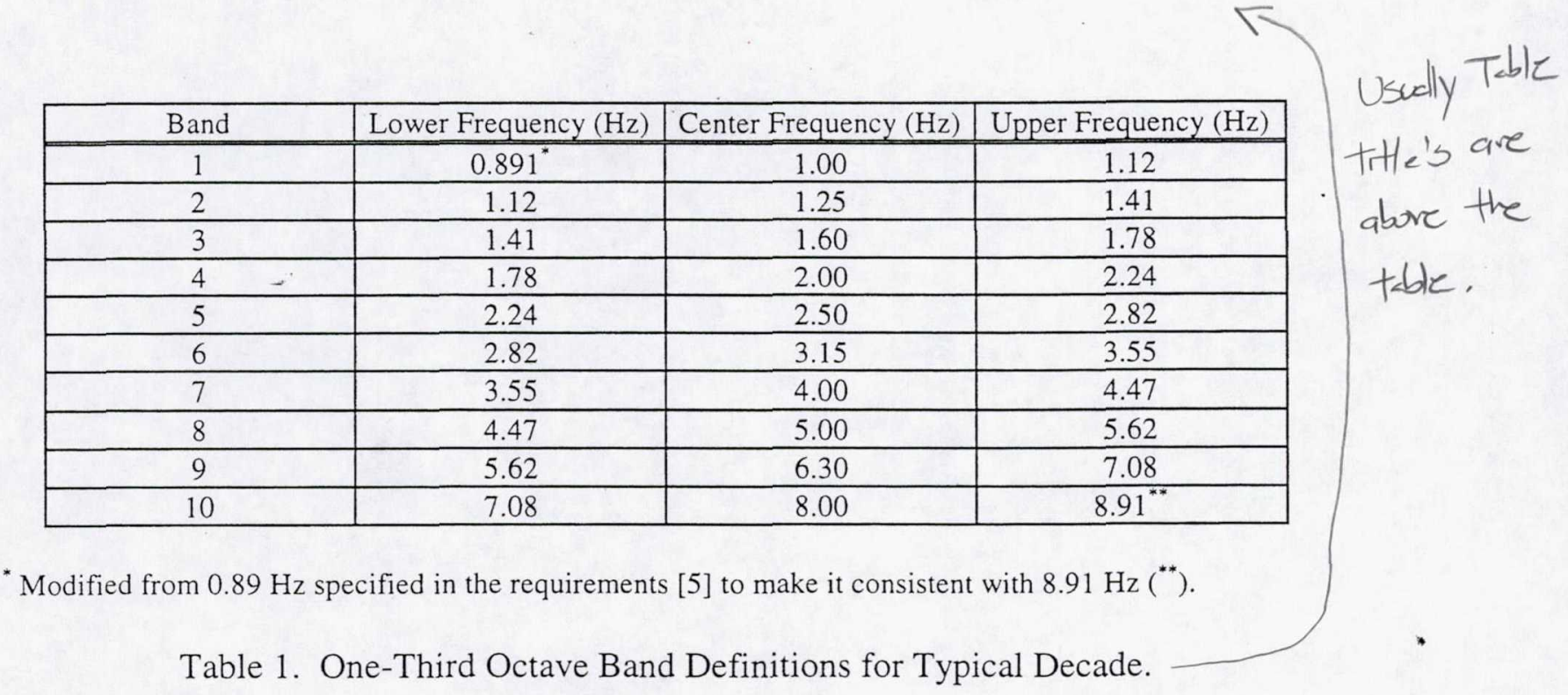

\begin{tabular}{|c|c|c|c|c|c|c|c|}
\hline $\begin{array}{l}\text { Sampling } \\
\text { Rate (Hz) }\end{array}$ & $\begin{array}{c}\text { No. of } \\
\text { Samples } \\
\text { for PSD }\end{array}$ & $\begin{array}{c}\text { No. of } \\
\text { Samples } \\
\text { for FFT }\end{array}$ & $\begin{array}{c}\text { Overlap } \\
\text { (User } \\
\text { Input) }\end{array}$ & $\begin{array}{c}\text { Overlap } \\
\text { (Actual) }\end{array}$ & $\begin{array}{c}\text { No. of } \\
\text { Averages } \\
\text { for PSD }\end{array}$ & $\begin{array}{c}\text { No. of } \\
\text { Samples } \\
\text { Used for } \\
\text { PSD }\end{array}$ & $\begin{array}{c}\text { Frequency } \\
\text { Resolution } \\
\text { (Hz) }\end{array}$ \\
\hline 100 & 10,000 & 4,096 & 2,048 & 2,128 & 4 & 10,000 & 0.0244 \\
\hline 500 & 50,000 & 16,384 & 8,192 & 7,980 & 5 & 50,000 & 0.0304 \\
\hline
\end{tabular}

Table 2. Typical Analysis Parameters Selected or Used in the Study. 


\begin{tabular}{|l|c|c|c|c|c|c|}
\hline \multicolumn{1}{|c|}{ Test Sessions } & Test Date & $\begin{array}{c}\text { Duration } \\
(\mathrm{min} .)\end{array}$ & $\begin{array}{c}\text { Samp. } \\
\text { Rate } \\
(\mathrm{Hz})\end{array}$ & $\begin{array}{c}\text { Filter } \\
\text { Rolloff } \\
(\mathrm{Hz})\end{array}$ & Gain & $\begin{array}{c}\text { Full } \\
\text { Scale } \\
(\mathrm{milli}-\mathrm{g})\end{array}$ \\
\hline \hline \multicolumn{7}{|c|}{ Mir Alone Configuration } \\
\hline \hline 1: Day-to-Night Transition & $11 / 27 / 96$ & 10 & 500 & 125 & 10 & 12 \\
\hline 2: Night-to-Day Transition & $12 / 11 / 96$ & 10 & 500 & 125 & 10 & 12 \\
\hline 3: Crew Exercise, Treadmill & $12 / 19 / 96$ & 10 & 500 & 125 & 5 & 24 \\
\hline 4: Crew IVA, Pushoffs & $12 / 20 / 96$ & 10 & 500 & 125 & 10 & 12 \\
\hline 5: Day-to-Night Transition & $12 / 23 / 96$ & 10 & 500 & 125 & 10 & 12 \\
\hline 6: Crew Exercise, Treadmill & $12 / 24 / 96$ & 10 & 500 & 125 & 5 & 24 \\
\hline 7: Mir Thruster Firing, IO Hold & $12 / 26 / 96$ & 20 & 100 & 25 & 5 & 24 \\
\hline 8: Crew IVA, Pushoffs & $12 / 27 / 96$ & 10 & 500 & 125 & 10 & 12 \\
\hline 9: Mir Thruster Firing, Gyrodyne & $12 / 30 / 96$ & 20 & 100 & 25 & 5 & 24 \\
\hline \hline \multicolumn{7}{|l|}{ Shuttle-Mir Mated Configuration } \\
\hline \hline 10: Shuttle-Mir Docking & $1 / 15 / 97$ & 30 & 100 & 25 & 1 & 120 \\
\hline 11: Mir Thruster Firing, IO Hold & $1 / 17 / 97$ & 20 & 100 & 25 & 1 & 120 \\
\hline 12: Crew Exercise, Treadmill & $1 / 17 / 97$ & 10 & 500 & 125 & 5 & 24 \\
\hline 13: Shuttle Thruster Firing & $1 / 17 / 97$ & 20 & 100 & 25 & 2 & 60 \\
\hline 14: Crew IVA, Pushoffs & $1 / 17 / 97$ & 10 & 500 & 125 & 10 & 12 \\
\hline 15: Night-to-Day Transition & $1 / 17 / 97$ & 10 & 500 & 125 & 10 & 12 \\
\hline 16: Day-to-Night Transition & $1 / 17 / 97$ & 10 & 500 & 125 & 10 & 12 \\
\hline
\end{tabular}

Table 3. First Phase MiSDE Test Description.

\begin{tabular}{|c|c|c|c|c|c|c|c|}
\hline \multirow[t]{2}{*}{ Test Sessions } & \multirow[t]{2}{*}{ Test Date } & \multicolumn{6}{|c|}{ Absolute Max. Accelerations Registered (milli-g) } \\
\hline & & Core & Kvant-1 & Priroda & Krystall & Kvant-2 & Spektr \\
\hline \multicolumn{8}{|c|}{ Mir Alone Configuration } \\
\hline 1: Day-to-Night Transition & $11 / 27 / 96$ & 12.51 & 3.32 & 9.01 & 1.57 & 4.96 & 0.67 \\
\hline 2: Night-to-Day Transition & $12 / 11 / 96$ & 11.94 & 3.03 & 9.20 & 2.34 & 6.37 & 1.28 \\
\hline 3: Crew Exercise, Treadmill & $12 / 19 / 96$ & 11.94 & 13.84 & 9.33 & 8.18 & 6.54 & 2.90 \\
\hline 4: Crew IVA, Pushoffs & $12 / 20 / 96$ & 12.32 & 3.73 & 2.83 & 1.82 & 3.56 & 0.72 \\
\hline 5: Day-to-Night Transition & $12 / 23 / 96$ & 12.05 & 3.37 & 5.71 & 1.40 & 2.70 & 1.47 \\
\hline 6: Crew Exercise, Treadmill & $12 / 24 / 96$ & 13.41 & 5.25 & 2.95 & 1.27 & 5.56 & 3.93 \\
\hline 7: Mir Thruster Firing, IO Hold & $12 / 26 / 96$ & 24.16 & 4.18 & 3.79 & 1.93 & 1.60 & 2.87 \\
\hline 8: Crew IVA, Pushoffs & $12 / 27 / 96$ & 11.49 & 3.26 & 5.39 & 0.88 & 4.95 & 0.65 \\
\hline 9: Mir Thruster Firing, Gyrodyne & $12 / 30 / 96$ & 15.79 & 5.80 & 2.84 & 8.44 & 3.34 & 3.15 \\
\hline \multicolumn{8}{|c|}{ Shuttle-Mir Mated Configuration } \\
\hline 10: Shuttle-Mir Docking & $1 / 15 / 97$ & 8.56 & 8.51 & 16.07 & 58.36 & 13.24 & 5.92 \\
\hline 11: Mir Thruster Firing, IO Hold & $1 / 17 / 97$ & 7.19 & 3.55 & 3.36 & 15.40 & 2.22 & 2.37 \\
\hline 12: Crew Exercise, Treadmill & $1 / 17 / 97$ & 13.51 & 5.93 & 1.83 & 3.38 & 2.94 & 1.01 \\
\hline 13: Shuttle Thruster Firing & $1 / 17 / 97$ & 3.74 & 1.51 & 1.14 & 5.35 & 0.73 & 0.84 \\
\hline 14: Crew IVA, Pushoffs & $1 / 17 / 97$ & 12.47 & 4.41 & 1.35 & 3.85 & 4.13 & 0.50 \\
\hline 15: Night-to-Day Transition & $1 / 17 / 97$ & 12.40 & 3.15 & 0.72 & 4.09 & 3.31 & 0.57 \\
\hline 16: Day-to-Night Transition & $1 / 17 / 97$ & 12.62 & 3.37 & 0.50 & 4.43 & 3.24 & 0.69 \\
\hline
\end{tabular}

Table 4. Maximum Time-Domain Response Levels. 


\begin{tabular}{|c|c|c|c|c|c|c|c|c|c|c|}
\hline \multirow{2}{*}{$\begin{array}{c}\text { Center } \\
\text { Freq. }(\mathrm{Hz})\end{array}$} & \multicolumn{10}{|c|}{ Test Session \# \& Max. One-Third Octave Band Responses (micro-g) } \\
\hline & $\# 5$ & $\# 6$ & $\# 7$ & \#8 & $\# 10$ & $\# 11$ & $\# 12$ & $\# 13$ & $\# 14$ & \#16 \\
\hline 0.040 & & & 32.9 & & 63.8 & 18.5 & & 12.5 & & \\
\hline 0.050 & 7.29 & 3.74 & 39.3 & 3.34 & 76.1 & 22.0 & 7.73 & 14.9 & 10.2 & 11.5 \\
\hline 0.063 & 8.62 & 4.43 & 34.2 & 3.95 & 83.8 & 23.7 & 9.15 & 14.5 & 12.1 & 13.6 \\
\hline 0.080 & 7.08 & 4.25 & 29.5 & 5.09 & 90.8 & 27.6 & 11.5 & 17.1 & 17.2 & 16.3 \\
\hline 0.100 & 6.49 & 4.78 & 23.1 & 5.85 & 91.4 & 39.7 & 14.7 & 37.8 & 23.4 & 22.3 \\
\hline 0.125 & 8.38 & 5.52 & 28.6 & 7.16 & 85.7 & 64.8 & 21.7 & 72.8 & 32.7 & 31.5 \\
\hline 0.160 & 8.57 & 6.63 & 39.0 & 7.91 & 111 & 56.0 & 31.1 & 65.0 & 28.6 & 31.8 \\
\hline 0.200 & 8.43 & 6.81 & 42.9 & 6.99 & 151 & 33.3 & 23.3 & 53.2 & 27.5 & 31.0 \\
\hline 0.250 & 10.0 & 7.85 & 57.1 & 8.94 & 135 & 69.8 & 15.8 & 94.9 & 18.1 & 17.8 \\
\hline 0.315 & 39.4 & 10.1 & 189 & 7.90 & 76.1 & 278 & 31.0 & 67.7 & 36.0 & 25.6 \\
\hline 0.400 & 21.6 & 10.9 & 103 & 10.3 & 286 & 354 & 16.9 & 26.9 & 25.4 & 31.3 \\
\hline 0.500 & 25.3 & 27.1 & 76.3 & 28.2 & 820 & 155 & 16.8 & 22.8 & 20.1 & 22.2 \\
\hline 0.630 & 24.2 & 173 & 55.2 & 36.4 & 1160 & 132 & 42.6 & 25.9 & 16.5 & 17.7 \\
\hline 0.800 & 58.6 & 103 & 160 & 128 & 742 & 303 & 226 & 199 & 79.8 & 106 \\
\hline 1.000 & 123 & 432 & 182 & 133 & 600 & 543 & 285 & 111 & 97.0 & 121 \\
\hline 1.250 & 91.8 & 787 & 1160 & 81.6 & 489 & 379 & 253 & 61.8 & 71.3 & 64.1 \\
\hline 1.600 & 42.0 & 181 & 700 & 35.0 & 478 & 194 & 118 & 54.0 & 47.2 & 35.9 \\
\hline 2.000 & 29.2 & 82.1 & 131 & 24.9 & 814 & 42.1 & 76.5 & 36.3 & 35.7 & 22.2 \\
\hline 2.500 & 15.7 & 99.9 & 31.5 & 17.0 & 128 & 43.6 & 118 & 34.9 & 23.5 & 13:6 \\
\hline 3.150 & 18.7 & 19.1 & 39.9 & 14.9 & 141 & 49.4 & 49.2 & 70.6 & 44.9 & 33.5 \\
\hline 4.000 & 37.0 & 193 & 103 & 11.2 & 164 & 51.3 & 77.5 & 27.3 & 19.6 & 20.3 \\
\hline 5.000 & 15.4 & 190 & 103 & 12.8 & 173 & 34.9 & 57.1 & 33.6 & 20.2 & 28.8 \\
\hline 6.300 & 15.8 & 45.6 & 134 & 14.1 & 157 & 48.2 & 65.7 & 26.2 & 16.1 & 20.9 \\
\hline 8.000 & 18.2 & 33.8 & 45.2 & 16.1 & 227 & 45.9 & 25.6 & 25.2 & 17.7 & 13.8 \\
\hline 10.00 & 25.6 & 29.4 & 70.9 & 19.7 & 549 & 46.2 & 45.3 & 32.7 & 25.0 & 26.2 \\
\hline 12.50 & 28.3 & 63.1 & 52.0 & 24.8 & 123 & 44.3 & 63.7 & 34.9 & 23.1 & 26.3 \\
\hline 16.00 & 26.0 & 59.6 & 49.6 & 30.5 & 106 & 39.8 & 64.9 & 33.6 & 26.9 & 24.2 \\
\hline 20.00 & 38.4 & 43.8 & 53.3 & 30.5 & 80.7 & 40.0 & 75.0 & 34.0 & 26.4 & 25.9 \\
\hline 25.00 & 1230 & 273 & 1080 & 1710 & 416 & 170 & 531 & 127 & 126 & 138 \\
\hline 31.50 & 57.1 & 81.5 & 49.7 & 54.7 & 121 & 51.0 & 251 & 46.5 & 53.6 & 53.5 \\
\hline 40.00 & 475 & 476 & 217 & 512 & 234 & 193 & 752 & 193 & 493 & 496 \\
\hline 50.00 & 4570 & 438 & & 4970 & & & 1410 & & 250 & 395 \\
\hline 63.00 & 258 & 263 & & 266 & & & 1200 & & 321 & 319 \\
\hline 80.00 & 560 & 498 & & 557 & & & 689 & & 358 & 371 \\
\hline 100.0 & 252 & 304 & & 254 & & & 516 & & 245 & 258 \\
\hline 125.0 & 141 & 132 & & 119 & & & 363 & & 116 & 117 \\
\hline 160.0 & 367 & 363 & & 381 & & & 574 & & 394 & 376 \\
\hline 200.0 & 198 & 193 & & 205 & & & 372 & & 227 & 203 \\
\hline
\end{tabular}

Table 5. Maximum One-Third Octave Band Response Levels. 
File: 3601_2 Accelerometer: Priroda T1 RSS(xyz)

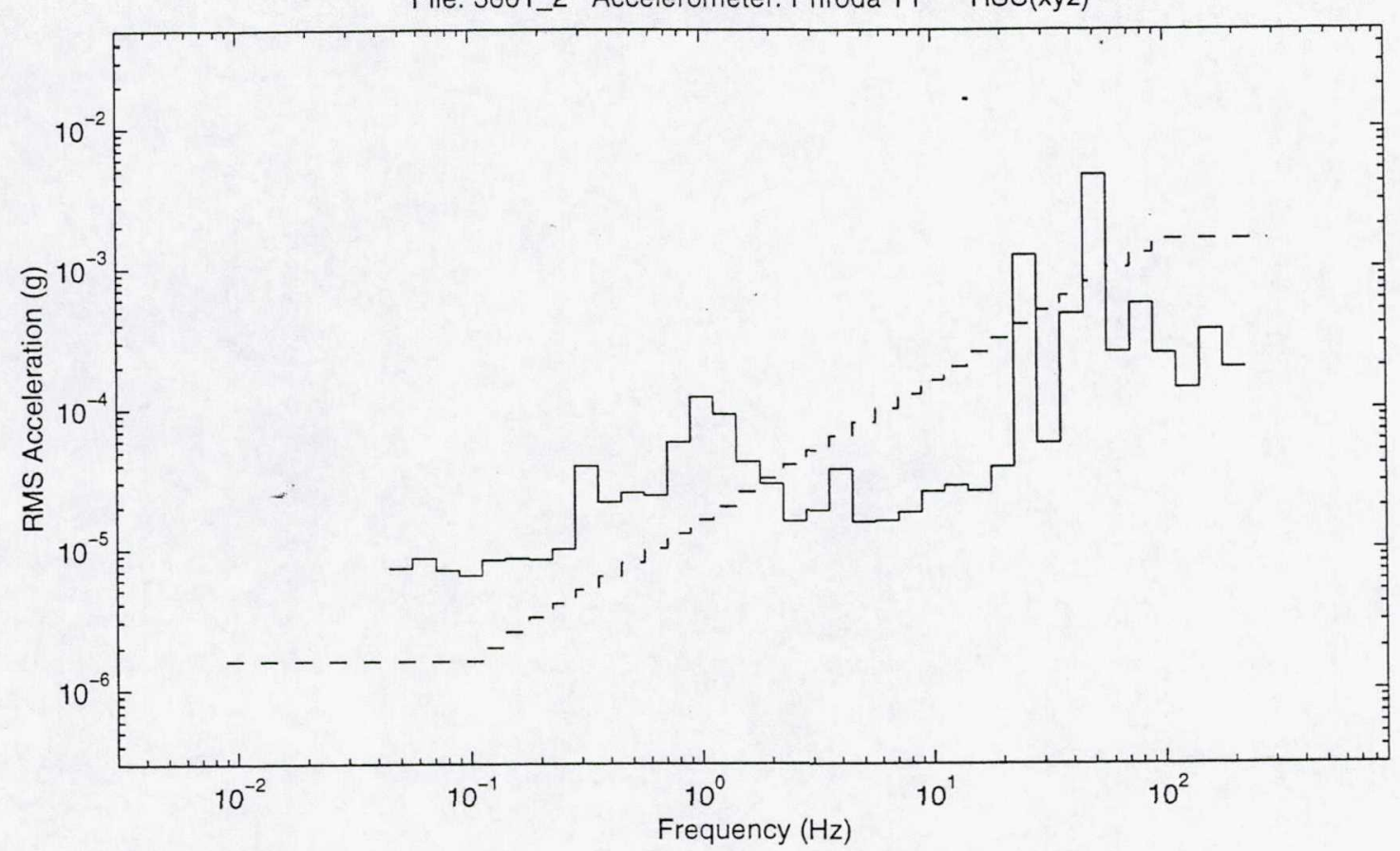

Figure 3 (a). Maximum One-Third Octave Band Plot for the Day-to-Night Session.

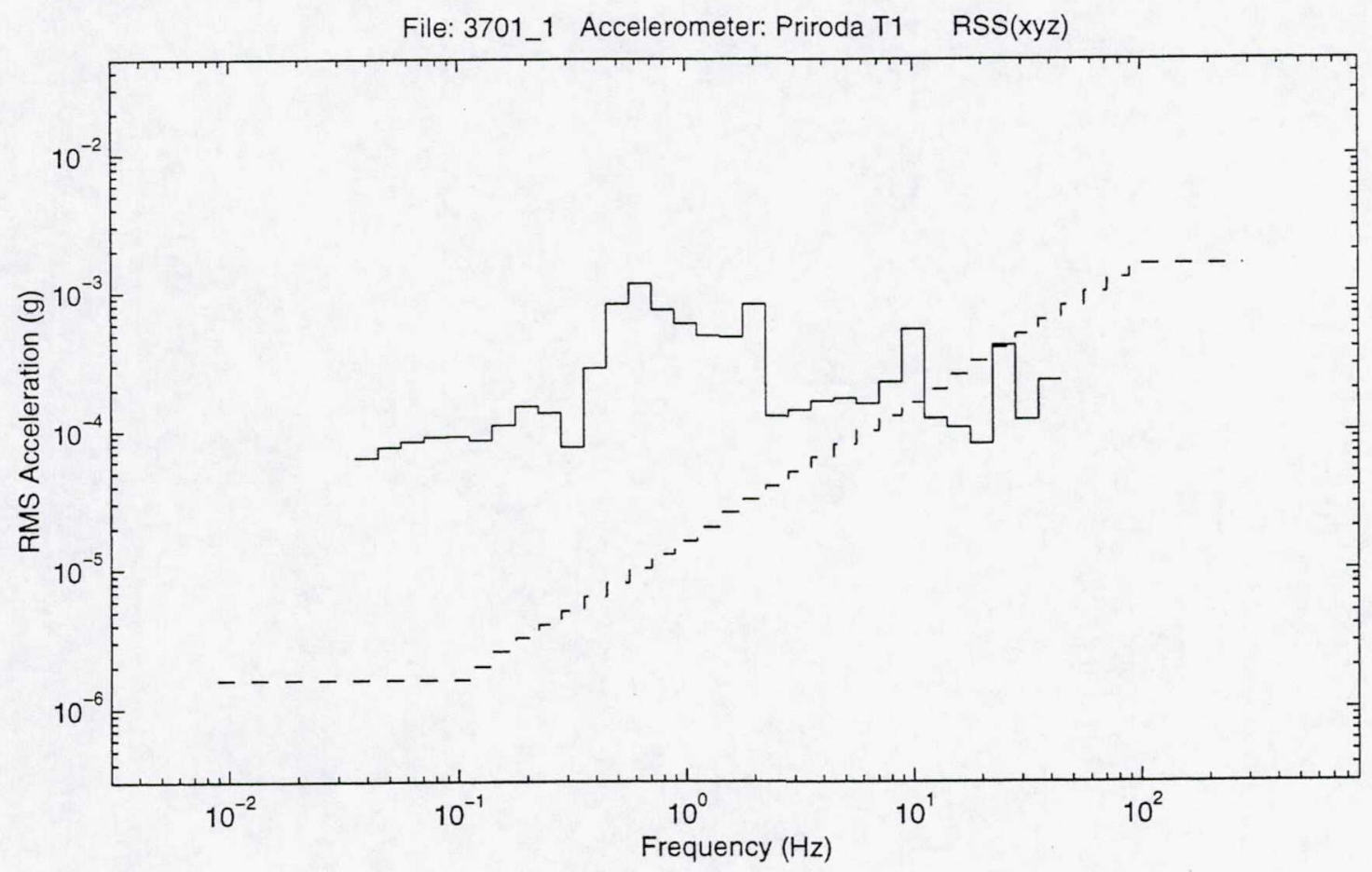

Figure 3 (b). Max. One-Third Octave Band Plot for the Shuttle-Mir Docking Session. 
File: 3641_1 Channel: Priroda Tri-1X

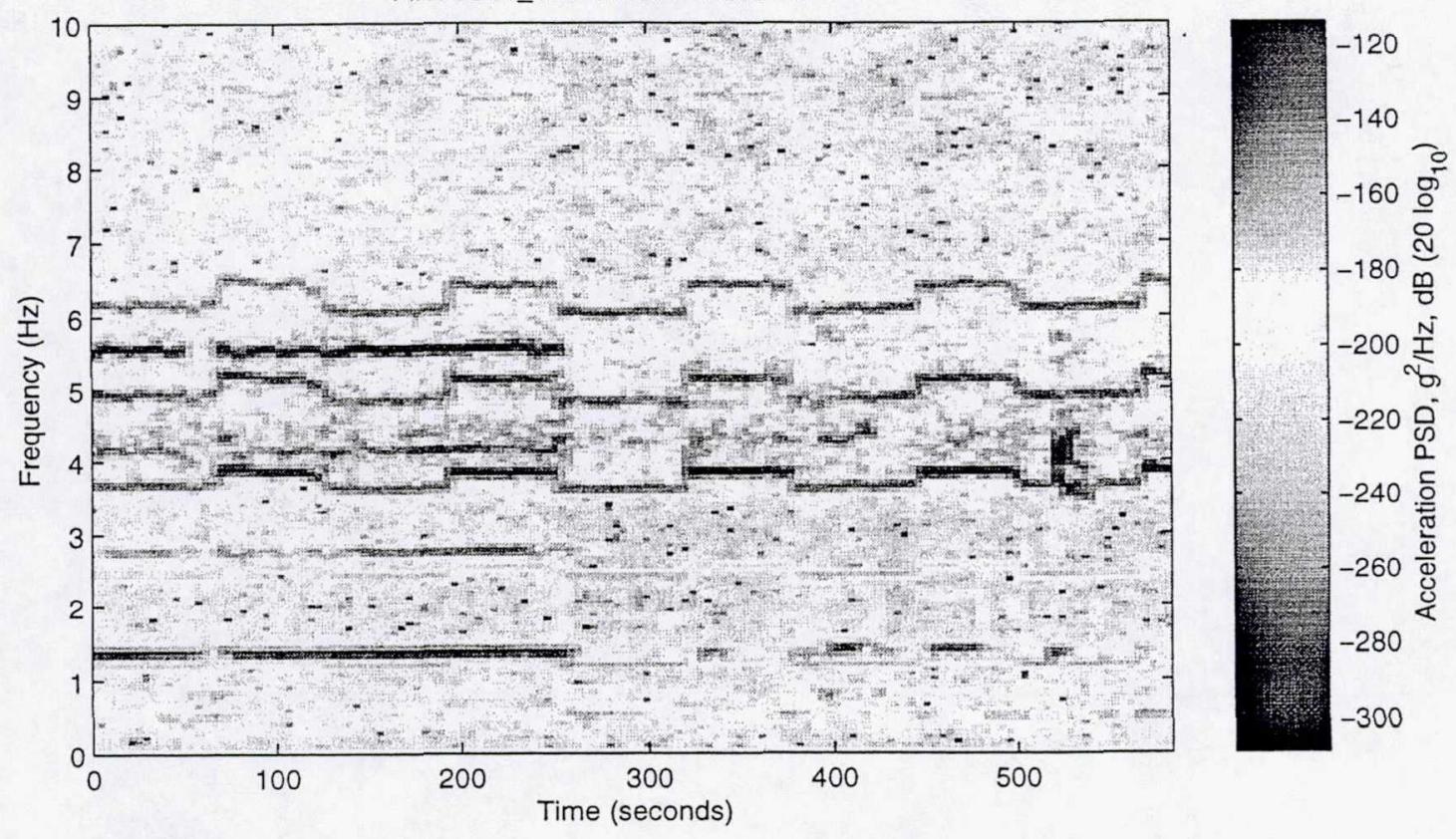

Figure 4 (a). Spectrogram Plot for the Crew Treadmill Exercise Session.

File: 3762_1 Channel: Priroda Tri-1X

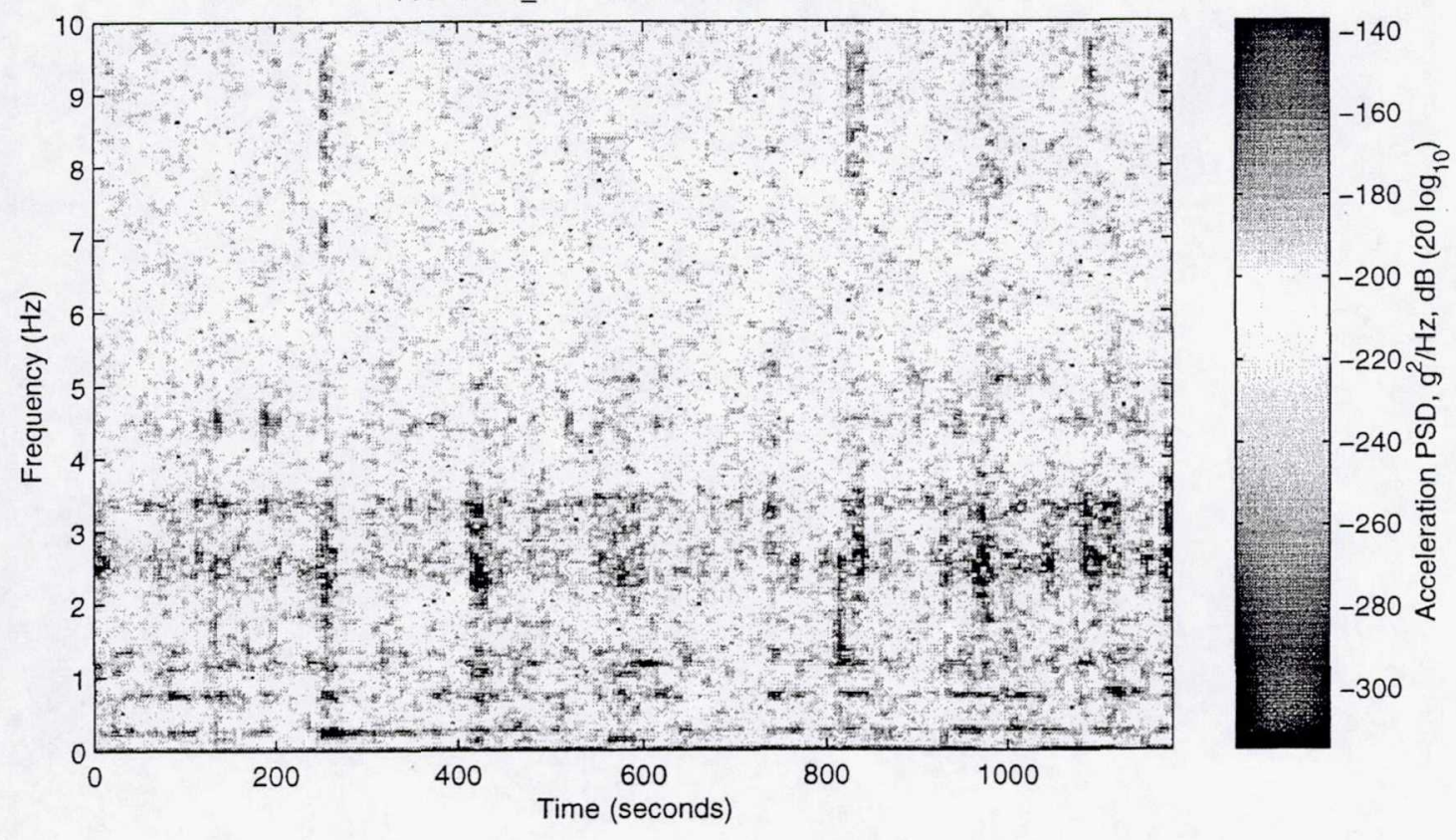

Figure 4 (b). Spectrogram Plot for the Shuttle Thruster Firing Session. 